ТИМОФССВ С. С., доктор техн. наук (УкрДУЗТ), СКЛЯРОВ М. В., канд. техн. наук (НАНГУ), ФЕДЧЕНКО І. І., канд. техн. наук (УкрДУЗТ), БУКІН Р. В., аспірант (УкрДУЗТ), ВОСКОБОЙНИКОВ Д. Г., аспірант (УкрДУЗТ)

\title{
Визначення швидкості зносу базових елементів вагонів у експлуатації
}

В статті проведено аналіз пасажирських $і$ вантажних вагонів, які подаються в плановий ремонт. В результаті досліджень зносу деталей вагонів розглянуто альтернативний підхід, який полягає у використанні комбінованого критерію, щзо обмежує міжремонтний період календарною тривалістю і виконаним обсягом роботи, вираженим в кілометрах пробігу вагона в прочесі експлуатації. Встановлено, щзо швидкості зносу базових елементів вагонів, приписаних до депо, дозволяють визначити потребу депо в запасних елементах при новій системі ремонту вагонів у залежності від їх пробігу.

Ключові слова: швидкість зносу, параметри оцінки, експлуатація, ремонт, розміри зношування, статистичні методи.

\begin{abstract}
Вступ
Залізничний транспорт $\epsilon$ однією 3 головних галузей промисловості України, він відіграє важливу роль у вантажних і пасажирських перевезеннях. Безпека пасажирських i вантажних перевезень залежить від технічного стану рухомого складу, і справності його вузлів та механізмів. Основне завдання експлуатації рухомого складу - вчасно виявляти несправності того чи іншого елементу вагона. До теперішнього часу подача вагонів у плановий ремонт здійснювалася за критерієм календарної тривалості їх експлуатації, який не оптимальний, так як вагони використовуються в перевізному процесі 3 різною інтенсивністю i, як наслідок, мають неоднаковий ступінь зносу на стадії подачі в ремонт. Альтернативою $є$ застосування комбінованого критерію, що обмежує міжремонтний період календарною тривалістю і виконаним обсягом роботи, вираженим в кілометрах пробігу вагона в процесі експлуатації. Перспективним методом, що характеризує інтенсивність зношування елементів вагонів, може бути розробка комбінованого критерію, тому розробка критерію на основі автоматизованої системи пономерного обліку пробігу вагонів $\epsilon$ актуальною. Для цього необхідно визначити гранично допустимі нормативи пробігу та строку експлуатації вагонів між деповськими ремонтами i єдиними технічними ревізіями.
\end{abstract}

\begin{abstract}
Аналіз останніх досліджень та публікацій
В роботах багатьох вітчизняних вчених приділялась значна увага вивченню причин виходу 3 ладу елементів вузлів та механізмів вагонів у процесі експлуатації [1-3]. В роботах [4-6] значна увага приділялась матеріалам та технологіям виготовлення деталей рухомого складу, поведінці їх в процесі експлуатації та технологіям відновлення геометричних розмірів. Крім того в роботі [7] здійснений аналіз методів оцінки оперативного контролю технічного стану колісних пар рухомого складу. Але незважаючи на велику кількість публікацій до теперішнього часу не розроблений метод автоматизованої системи пономерного обліку пробігу вагонів 3 урахуванням реальних умов експлуатації.
\end{abstract}

Метою роботи була розробка комбінованого критерію на основі автоматизованої системи пономерного обліку пробігу вагонів 3 урахуванням реальних умов експлуатації, інтенсивності використання та зносу деталей і вузлів рухомого складу на основі статистичних даних. 


\section{Основна частина досліджень}

Для розробки комбінованого критерію на основі автоматизованої системи пономерного обліку пробігу вагонів 3 урахуванням реальних умов експлуатації та інтенсивності використання, на основі статистичних даних вагони були розділені на три групи. Перша (12 вагонів) i друга (14 вагонів) групи були укомплектовані вагонами з терміном служби не більше 13 років на момент початку експерименту і закріплені для постійного цілорічного використання за складами поїздів 3 прогнозованим річним пробігом 425...435 і $165 \ldots 215$ тис. км відповідно. Третя група (14 вагонів) була укомплектована вагонами, які відслужили вже понад 13 років на момент початку експерименту, які експлуатувалися без закріплення за певним складом, в тому числі сезонно, без прогнозування їх річного пробігу.

Необхідно організувати натурне спостереження за станом вузлів і деталей вагонів у процесі експерименту і облік величини трудових, матеріальних і фінансових витрат на деповський ремонт, єдину технічну ревізію $\mathrm{i}$ поточний ремонт. На всіх вагонах перед введенням їх в дослідну експлуатацію були проведені вимірювання розмірів базових елементів, які зношуються. Результати замірів перед початком експерименту і в процесі його проведення фіксувалися в спеціальних картах і використовувалися для визначення середньої швидкості зносу елементів вагона.

При аналізі результатів вимірювання поверхонь, що зношуються, базових елементів вагонів оцінку значення математичного очікування i дисперсії швидкості зносу базових елементів вагона проводили за двома варіантами.

При першому варіанті оцінка параметрів (середньої швидкості зносу, дисперсії швидкості зносу i коефіцієнта варіації) проводилася за формулами математичної статистики без урахування впливу експлуатаційних факторів на значення зазначених параметрів. За співвідношенням цих статистичних параметрів між собою визначали закон розподілу випадкових величин (величин зносу базових елементів вагона).

Визначення статистичного значення середньої швидкості зносу базового елемента проводили за формулою

$$
M\left(\bar{Y}_{i}\right)=\frac{1}{N} \sum_{j=1}^{N} \bar{Y}_{i j} \ldots
$$

де $\mathrm{Y} i$ - середня швидкість зносу $i$-го елемента (наприклад, для восьми втулок шпінтона), визначена за вибіркою з $N$ дослідних вагонів $(j=1,2,3, \ldots N)$; $Y_{i j}$ середня швидкість зносу $i$-го елемента (втулки шпінтона) на одному $j$-му вагоні з $N$ вагонів, що беруть участь в експерименті, при $l j$ кілометровому пробігу.
В (1) середня швидкість зносу $i$-го елемента (наприклад, втулки шпінтона) для $j$-го вагона при його пробігу $l j$ визначалася як

$\bar{Y}_{i j}=\frac{\left|\left(z_{i j}\right) l_{0}-\left(z_{i j}\right) l_{j}\right|}{l_{j}}$

де $\left(Z_{i j}\right)$ lo - початкові розміри $i$-го елемента (втулки шпінтона) на $j$-му вагоні при випуску $з$ деповського ремонту (ДР) або з заводу (при lo = 0 км пробігу); $\left(Z_{i j}\right) l j$ - проміжні або кінцеві розміри $i$-го елемента на $j$-му вагоні, заміряні при пробігу $l j$.

Визначення статистичного значення дисперсії випадкової величини швидкості зносу базового $i$-го елемента по $N$ вагонах визначалося за виразом

$$
S^{2}\left(\bar{Y}_{i}\right)=\frac{1}{N-1} \sum_{j=1}^{N}\left(\bar{Y}_{i j}-\bar{Y}_{i}\right)^{2}
$$

Статистичне значення коефіцієнта варіації швидкості зносу (базового) $i$-го елемента для пасажирського вагона визначалося як

$$
V\left(\bar{Y}_{i}\right)=S\left(\bar{Y}_{i}\right) / M\left(\bar{Y}_{i}\right)
$$

За значенням середньої швидкості зносу і іiі середньоквадратичного відхилення встановлювався дослідний міжремонтний норматив пробігу $L_{\rrbracket}$ пасажирського вагона в міжремонтний період відповідно до формули

$$
\frac{\left(\Delta Z_{i}\right)_{H}}{\left[M\left(\bar{Y}_{i}\right)+s\left(\bar{Y}_{j}\right)\right]} \geq\left(a_{\mathrm{M}}\right), \text { тис. км }
$$

де $\left(\Delta Z_{i}\right)_{H}-$ нормативна (допустима за технічною документацією) величина зносу елемента вагона за міжконтрольний період (наприклад, за міжремонтний період до ДР).

За значенням коефіцієнта варіації можна дати оцінку закону розподілу випадкової величини швидкості зносу базового елементу вагона. Якщо це співвідношення близьке до одиниці (або дорівнює 1), то це вказує на показовий розподіл випадкової величини. Для втулок шпінтона співвідношення (4), як було визначено за результатами обробки результатів дослідної експлуатації 12 пасажирських вагонів, знаходиться в межах 0,2...0,7. Це вказує на близькість до нормального закону розподілу середньої швидкості зносу втулки шпінтона.

Значення середньої швидкості зносу, іiі дисперсії, коефіцієнта варіації для деяких базових елементів вагона, отримані за наведеними вище формулами, дані в табл. 1. 
Отримані значення середньої швидкості зносу і дисперсії показують, що для деяких елементів вагона (втулки шпінтона, клинів-сухарів, серег, що центрують балочки тощо.) необхідно зменшити їх швидкість зносу і відповідно збільшити міжремонтний пробіг вагона до деповського ремонту. Це проводиться шляхом наплавлення твердого сплаву на зношені поверхні елементів.

Задані дослідні пробіги вагонів для проведення єдиної технічної ревізії (160 тис. км) і деповського ремонту (320 тис. км) забезпечували безпечну експлуатацію вагонів i дозволили ввести їх як нормативні міжремонтні пробіги. Нормативні значення пробігів рівні: для ТО-3 - 150 ... 165 тис. км; для ДР - 300 ... 330 тис. км.

Проведені під час проведення експерименту виміри зносів і певні швидкості зносів елементів вагона показали необхідність введення в депо вхідного контролю твердості замінних елементів вагона (втулки шпінтона, клинів-сухарів, серег і т. д.).

При другому варіанті оцінка значення середньої швидкості зносу $Y$ або середньої величини зносу $Z$ елементів вагона проводилася 3 урахуванням впливу експлуатаційних факторів: котельної та некотлового боку (візки) вагона $-X_{1}$, вигляду вагона (плацкартний і купейний) $-X_{2}$, маршруту слідування вагона $-X_{3}$. Ці фактори i знос базових елементів вагона фіксувалися і були включені при обробці результатів в матрицю планування активного екстремального експерименту. Матриця наведена в табл. 2.

Фактори в матриці планування варіювалися на двох крайніх рівнях:

верхньому, або максимальному, умовно позначеному через плюс («+»); нижньому, або мінімальному, умовно позначеному через мінус («-»).

Для виявлення суттєвості впливу зазначених вище факторів i виду функціонального зв'язку між величиною зносу i експлуатаційними чинниками подавали цю залежність (для подальшої іiі перевірки) у вигляді поліноміальної математичної моделі

$\bar{Z}=B_{0} X_{0}+B_{1} X_{1}+B_{2} X_{2}+B_{3} X_{3}+B_{1,2} X_{1,2}+$ $+B_{2,3} X_{2,3}+B_{1,3} X_{1,3}+B_{1,2,3} X_{1,2,3}$,

де $\bar{Z}$ - середнє значення функції (величини зносу) в залежності від впливу трьох експлуатаційних факторів $\left(X_{1} ; X_{2} ; X_{3}\right) ; B$ - коефіціснти регресії, значення яких показує істотність впливу на функцію $Z j$-го фактора або взаємодії факторів; $X$ - $j$-й фактор, який впливає на досліджувану функцію ( $i$ - взаємодії факторів, що вказують вплив на функцію $\bar{Z}$ ).
Остаточний вигляд регресійного рівняння (6) встановлювався статистичною обробкою результатів експерименту (спостережень).

Перед проведенням експерименту необхідно було попередньо встановити, якими факторами (їх рівнями) можна управляти (або регулювати їх значення), а якими керувати неможливо і тільки можна фіксувати їх значення в експерименті. У будь-якому випадку рівні факторів в експерименті повинні фіксуватися в документах (в журналі обліку спостережень, картках обліку пошкоджень).

На підставі регресійного рівняння (6) планувався експеримент (випробування вагонів) або проводилася вибірка 3 результатів експерименту 3 подальшою їх обробкою.

При плануванні експерименту i спостережень відповідно до теорії активного екстремального експерименту і рівнянь регресії (6) число об'єктів спостереження і число дослідів має дорівнювати

$N=2^{b} m=24$,

де $b$ - число факторів, включених в рівняння регресії для виявлення суттєвості їх впливу на функцію $Z$ (знос); 2 - числа фіксованих ( «+» максимальних і «-» мінімальних) значень досліджуваних експлуатаційних факторів (два рівні); число повторень дослідів (приймається зазвичай рівним трьом або більше) для визначення дисперсії досліджуваної величини $Z$.

В експерименті число повторень дослідів $m$ варіювалося залежно від числа однакових елементів на візку або вагоні.

План експерименту по вагонах i їх базових елементів подано у вигляді табл. 2 (матриці планування). 
Таблиця 1

Розміри елементів вагонів та параметри зносу

\begin{tabular}{|c|c|c|c|c|c|}
\hline \multirow[b]{2}{*}{ Найменування } & $\begin{array}{c}\text { Розміри елементів } \\
\text { вагона }\end{array}$ & \multicolumn{4}{|c|}{ Значення параметрів зносу } \\
\hline & $\begin{array}{c}\text { Конструктивні } \\
\text { (номінальні) розміри } \\
\text { Допустимі розміри } \\
\text { при випуску з } \\
\text { деповського } \\
\text { ремонту, мм }\end{array}$ & $\begin{array}{l}\text { Граничні } \\
\text { зноси } \\
\text { елементів, } \\
\text { мм }\end{array}$ & $\begin{array}{c}\text { Середня } \\
\text { швидкість } \\
\text { зносу, мм/тис. } \\
\text { км, } \bar{y}\end{array}$ & $\begin{array}{c}\text { Середнє } \\
\text { квадратичне } \\
\text { відхилення } \\
\text { швидкості зносу, } \\
\text { мм/тис. км, } G ;\end{array}$ & $\begin{array}{c}\text { Коефіцієнт } \\
\text { варіації } V\end{array}$ \\
\hline $\begin{array}{c}\text { Шпінтон: } \\
\text { зовнішній діаметр }\end{array}$ & $\frac{\$ 67-2,0}{\Phi 63-2,0}$ & 0,2 & 0,0006 & 0,0006 & 1,0 \\
\hline $\begin{array}{l}\text { Втулка шпінтона: } \\
\text { зовнішній діаметр }\end{array}$ & $\frac{\Phi 89.5-2,5}{\Phi 87-2,5}$ & $4,0 \ldots 9,5$ & 0,0060 & 0,0030 & 0,5 \\
\hline $\begin{array}{l}\text { Серга внутрішня: } \\
\text { опорні поверхні }\end{array}$ & $\frac{229+2}{232+2}$ & $1,5 \ldots 6,0$ & 0,0013 & 0,0026 & 2,0 \\
\hline $\begin{array}{c}\text { Надресорна балка:отвори } \\
\text { втулок в кронштейнах для } \\
\text { гідрогасителя }\end{array}$ & $\frac{\$ 32+0.17}{\$ 34+0.17}$ & $1,9 \ldots 3,8$ & 0,0016 & 0,0007 & 0,4 \\
\hline $\begin{array}{c}\text { Підвіска башмака: } \\
\text { отвори втулок: } \\
\text { верхньої } \\
\text { нижньої } \\
\text { вушка }\end{array}$ & $\begin{array}{l}\frac{\$ 32+0,34}{\Phi 34+0,34} \\
\frac{\$ 5+0,2}{\$ 57+0.2} \\
\Phi 14+0,24 \\
\Phi 16+0,24\end{array}$ & $\begin{array}{c}2,7 \\
2,2 \\
1,0 . .3,1\end{array}$ & $\begin{array}{l}0,0009 \\
0,0009 \\
0,0016\end{array}$ & $\begin{array}{l}0,0002 \\
0,0005 \\
0,0009\end{array}$ & $\begin{array}{l}0,3 \\
0,6 \\
0,6\end{array}$ \\
\hline $\begin{array}{c}\text { Траверса гальмової } \\
\text { важільної передачі: } \\
\text { зовнішній діаметр втулок }\end{array}$ & $\frac{55^{-0.6}}{54_{-0,6}^{-0.2}}$ & $1,0 \ldots 1,8$ & 0,0015 & 0,0006 & 0,4 \\
\hline $\begin{array}{c}\text { товщина перемички } 3 \\
\text { боку отвору для клина } \\
\text { ширина отвору «Г» }\end{array}$ & $\begin{array}{l}\frac{58+3}{58} \\
\frac{140+4}{144}\end{array}$ & $\begin{array}{l}3,0 \ldots 4,1 \\
3,0 \ldots 7,0\end{array}$ & $\begin{array}{l}0,0063 \\
0,0112\end{array}$ & $\begin{array}{l}0,0086 \\
0,0073\end{array}$ & 0,6 \\
\hline довжина хомута & $\frac{744+4}{744}$ & $4,0 . .6,0$ & 0,0107 & 0,0069 & 0,6 \\
\hline $\begin{array}{c}\text { Клин тягового хомута: } \\
\text { товщина/ } \\
\text { ширина }\end{array}$ & $\begin{array}{l}\frac{33,5-1}{30} \\
\frac{95-2}{89}\end{array}$ & $1,6 \ldots 2,5$ & 0,0058 & 0,0011 & 0,19 \\
\hline $\begin{array}{c}\text { Центруюча балочка: } \\
\text { висота перетину «Н» в } \\
\text { місці опори хвостовика } \\
\text { автозчепного пристрою }\end{array}$ & $\frac{165-1}{160}$ & $3,1 \ldots 6,5$ & 0,0046 & 0,0071 & 1,5 \\
\hline
\end{tabular}


У табл. 2 стовпчики $X_{1}, X_{2}, X_{3}$ задають план (умови) випробувань (експлуатації); «+» - це умовне позначення верхнього (максимального) значення експлуатаційного фактора в цьому досліді (рейсі); «-» - це умовне позначення нижнього (мінімального) значення експлуатаційного фактора; стовпці $X_{0} ; X_{1,2}$;
$X_{2,3} ; X_{1,3} ; X_{1,2,3}$ служать тільки для розрахунку (обробки результатів) і означають вплив на функцію $Z$ (знос елемента - його середнє значення) взаємодії факторів $Z_{1}, Z_{2}, Z_{3}$-це значення функції (зносу елемента) в кожному 3 трьох або більше повторень дослідів .

Таблиця 2

\section{Матриця планування повнофакторного експерименту}

\begin{tabular}{|l|l|l|l|l|l|l|l|l|l|l|l|l|l|l|l|}
\hline \multicolumn{10}{|c|}{ Матриця планування повнофакторного експерименту } \\
\hline $\begin{array}{l}\text { Номер } \\
\text { вагона }\end{array}$ & \multicolumn{10}{|c|}{$\begin{array}{c}\text { Величина зносу втулок шпінтона в } \\
\text { кожному з дослідів, мм }\end{array}$} \\
\hline & $X 0$ & $X 1$ & $X 2$ & $X 3$ & $X 1,2$ & $X 2,3$ & $X_{13}$ & $X 1,2,3$ & $Z_{1}$ & $Z_{2}$ & $Z_{3}$ & $\ldots$ & $Z$ \\
\hline 1 & + & - & - & - & + & + & + & - & 1,9 & 2,3 & 2,7 & $\ldots$ & 2,7 \\
\hline 2 & + & + & - & - & - & + & - & + & 2,8 & 2,3 & 2,0 & $\ldots$ & 2,2 \\
\hline 3 & + & - & + & - & - & - & + & + & 0,7 & 3,7 & 0,9 & $\ldots$ & 1,8 \\
\hline 4 & + & + & + & - & + & - & - & - & 2,6 & 3,0 & 2,6 & $\ldots$ & 2,1 \\
\hline 5 & + & - & - & + & + & - & - & + & 3,9 & 2,7 & 0,9 & $\ldots$ & 2,2 \\
\hline 6 & + & + & - & + & - & - & + & - & 1,0 & 1,0 & 0,5 & $\ldots$ & 1,0 \\
\hline 7 & + & - & + & + & - & + & - & - & 1,3 & 0,8 & 0,8 & $\ldots$ & 0,7 \\
\hline 8 & + & + & + & + & + & + & + & + & 1,1 & 1,5 & 1,7 & $\ldots$ & 1,4 \\
\hline
\end{tabular}

Точність отриманої в результаті випробувань регресійної залежності (6) зносу базового елементу вагона від пробігу, стану колії на маршруті (номер 63 і 98), роду вагона, сторони вагона визначалася точністю (дисперсією) коефіцієнтів регресії - В. Дисперсія цих коефіцієнтів визначалася за формулою

$S^{2}\left(B_{j}\right)^{\mathrm{BT}}=\frac{s_{\pi}^{2}(\bar{Z})^{\mathrm{BT}}}{N m}=\frac{s_{\Pi}^{2}(\bar{Z})^{\mathrm{BT}}}{24}$

При $m=3 ; N=8$,

де $S_{\mathbb{I}}^{2}(\bar{Z})^{\mathbb{E}}$ повна середня дисперсія експерименту (наприклад, для втулки шпінтона):

$$
\begin{aligned}
& S_{\Pi}^{2}(\bar{Z})^{\overline{\mathrm{IT}}}=\frac{\sum_{j=1}^{N=8} \sum_{Q=1}^{n=3+9}\left(Z_{q}^{\mathrm{ET}}-\bar{Z}_{j}^{\mathrm{BT}}\right.}{N(n-1)}= \\
& =\frac{\sum_{j}^{N=8} s_{j}^{2}(\bar{Z})^{\mathrm{ET}}}{N} .
\end{aligned}
$$

Перед визначенням повної середньої дисперсії $S_{\mathbb{I I}}^{2}(\bar{Z})^{\mathrm{BT}}$ проводилася перевірка однорідності дисперсій в кожному з восьми дослідів (j-му вагоні) за критерієм Кохрена (так як число порівнюваних дисперсій більше двох, а число повторень дослідів у кожній точці плану однаково). Дисперсію в кожній точці подано як

$$
S_{j}^{2}(\bar{Z})^{\mathrm{ET}}=\frac{\sum_{q=1}^{m=\mathrm{a}+\mathrm{q}}\left(z_{q}^{\mathrm{mT}}-\bar{Z}_{j}^{\mathrm{aT}}\right)}{m-1}
$$

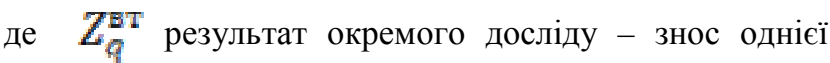
деталі в $j$-му вагоні або в $j$-му рядку; $m$ - число повторень дослідів або число однакових елементів на вагоні $(q=1,2,3, \ldots, m)$.

Однорідність дисперсії визначалася з виразу

$$
G=\frac{s_{j \max }^{2}\left(\overline{\mathbf{Z}}_{j}\right)^{\mathrm{BT}}}{\sum_{j=1}^{N} s_{j}^{2}\left(\overline{\mathbf{Z}}_{j}\right)^{\mathrm{ET}}}<G_{\mathrm{Ta} \sigma \mathrm{I}}
$$

$(N=8 ; m=3 ; \alpha=0,05)$,

де $\mathrm{G}_{\text {таблл }}=0,6530$; якщо умова (11) дотримується, то дисперсії однорідні, в іншому випадку результати досліду 3 більшою дисперсією аналізуються i перевіряються на їх достовірність.

Значення коефіцієнтів регресії визначалося за формулою (для будь-якого числа досліджуваних факторів)

$B_{i}=\frac{1}{N} \sum_{j=1}^{N} \bar{Z}_{j}^{B T} X_{i j}$ 
де $i=1,2,3, \ldots, \kappa-$ номер досліджуваного фактора; $\bar{Z}_{j}^{\text {עт }}$ - середнє значення функції (зносу) в кожній $j$-й точці плану.

У нашому експерименті коефіцієнти розраховані як

$$
\begin{aligned}
& B_{0}=\frac{\Sigma_{1}^{\mathrm{a}} \bar{Z}_{j}^{\mathrm{az}}}{\mathrm{g}} ; B_{i}=\frac{\Sigma_{1}^{\mathrm{a}} \bar{Z}_{j}^{\mathrm{az}}}{\mathrm{g}} \\
& B_{1,2}=\frac{\Sigma_{1}^{\mathrm{g}} \bar{z}_{j}^{\mathrm{ar}} X_{2 j} X_{2 j}}{9} ; B_{1,3}=\frac{\Sigma_{1}^{\mathrm{a}} \bar{Z}_{j}^{\mathrm{nT}} X_{2 j} X_{3 j}}{8}, \\
& B_{2,3}=\frac{\Sigma_{1}^{\mathrm{g}} \bar{Z}_{j}^{\mathrm{g} \tau} X_{2 j} X_{3 j}}{\mathrm{~g}}, B_{1,2,3}=\frac{\Sigma_{1}^{\mathrm{g}} \bar{z}_{j}^{\mathrm{a} \pi} X_{1 j} X_{\mathrm{z} j} X_{\mathrm{z} j}}{\mathrm{~g}}
\end{aligned}
$$

Значимість коефіцієнтів регресії (і включення їх в рівняння регресії) перевірялася за критерієм Стьюдента $t_{N \alpha}$; табличне значення цього критерію при числі ступенів свободи (зокрема дослідів без повторень) $N=f=8$ і рівні значущості $\alpha=0,05$ дорівнює: $t=2,31$ (при $f=8 ; \alpha=0,05$ ).

Коефіцієнти вважаються значущими, якщо їх абсолютні величини більше довірчого інтервалу

$\Delta b=2 t S(b i)$.

Після остаточного встановлення рівняння регресії проводилася перевірка адекватності отриманого рівняння (див. далі формулу (17) за критерієм Фішера (дисперсійним відношенням)

$F=\frac{s_{(\mathrm{za})}^{2}{ }^{\mathrm{ET}}}{s_{\mathrm{n}}^{2}\left(\overline{z)^{\mathrm{ET}}}\right.}<F_{\mathrm{rab \pi}}$,

при $f_{1}=N-1 ; f_{2}=N=8 ; \propto=0,05$

де $F_{\text {табл }}=F(3 ; 8 ; 0,05)=4,07 ; 1$-число значущих коефіцієнтів у рівнянні регресії, включаючи $\mathrm{B}_{0}$; $S_{(\text {aд) }}^{2}$ इ рівнянням

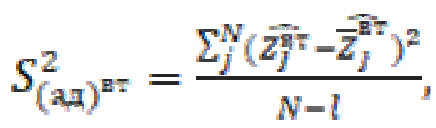

де $Z_{j}^{\mathbb{E x}}$ значення зносу елемента вагона (втулки шпінтона) на $j$-му вагоні (в кожному рядку плану табл. 2), отримане за дослідним рівнянням (див. далі формулу (17) при підстановці значень факторів («+» або «-»), зазначених в табл. $2 ; Z_{j}^{\text {sT }}$-середнє значення зносу елемента вагона (втулки шпінтона), отримане за дослідним рівнянням (див. далі формулу (17) для $N$ вагонів (при $N=8$ ).

Отримане рівняння регресії для елемента вагона можна використовувати при визначенні термінів проведення відповідних видів ремонту базових елементів вагона. Так, для втулки шпінтона (елемент буксового підвішування у візку, залежність між середньою величиною зносу $Z^{\text {вт }}$ i трьома вищевказаними факторами при середньому пробігу вагонів 324,8 тис. км після обробки результатів експерименту має вигляд

$\bar{Z}^{\mathrm{sT}}=2,0 X_{0}-0,12 X_{1}-0,25 X_{2}-0,45 X_{3}+0,35 X_{1} X_{2}$

Отримане рівняння не суперечить гіпотезі про адекватність експериментальним даним.

Всі коефіцієнти регресії значущі, залежність (17) через значущості коефіцієнта взаємодії $\mathbf{B}_{1,2}$ факторів $X$ і $X_{2}$ нелінійна, тому використовувати це рівняння для прогнозу зносу (або швидкості зносу) важко. Для втулки шпінтона в цьому випадку можна використовувати отримане вище (за першим варіантом) значення середньої швидкості зносу на тисячу кілометрів (тис. км) пробігу.

Аналогічно було отримано рівняння регресії для опорної поверхні серег центрального ресорного підвішування візка

$$
\bar{Z}^{\text {серьг }}=0,56 X_{0}+0,16 X_{1}-0,14 X_{3}-0,19 X_{1} X_{3}-0,24 X_{2} X_{3} .
$$

Залежність (18), як і попередня, нелінійна, так як коефіцієнти взаємодії ( $\mathrm{B}_{1,3}$ та $\mathrm{B}_{2,3}$ ) значимі. Отже, практично використовувати це рівняння для прогнозу зносу важко. Однак можна сказати, що з усіх факторів на знос поверхні серги вид вагона, тобто фактор $X_{2}$ (плацкартний або купейний), не має істотного значення, і його можна виключити зі спостережень.

Аналогічно для кожного базового елементу вагона, за яким встановлено періодичні спостереження (періодичні заміри зносів), можна визначити рівняння регресії за наведеними вище залежностями.

Даний метод планування випробувань і обробки матеріалів 3 теорії екстремального експерименту має низку переваг перед іншими методами, основним 3 яких $\epsilon$ отримання регресійної залежності (математичної моделі). 3 цієї залежності, отриманої в результаті обробки статистичних даних експерименту, можна прогнозувати технічний стан вагонів та їх базових елементів. 
У разі відсутності в експериментальних даних значень зазначених факторів наведений математичний апарат використовується для визначення тільки середніх значень зносів базових елементів вагона в залежності від пробігу вагонів без отримання регресійної залежності.

\section{Висновки}

Для оцінки технічного стану елементів вагона слід використовувати розглянутий математичний апарат формул (6) ... (16) і матрицю планування, наведену в табл. 2. Цей варіант найбільш ефективний, тому що в порівнянні 3 іншими методами дає оцінку шуканого параметра 3 меншою дисперсією. Використовуючи метод оцінки досліджуваного параметра (швидкості зносу) базових елементів вагона $з$ урахуванням впливу експлуатаційних факторів, ремонтні підприємства можуть визначати оптимальні терміни заміни базових елементів для своїх приписних вагонів. Швидкості зносу базових елементів пасажирських вагонів, приписаних до депо дозволяють визначити потребу депо в запасних елементах при новій системі ремонту вагонів у залежності від їх пробігу.

\section{Список використаних джерел}

1. Тененбаум М. М. Износостойкость конструкционных материалов и деталей машин. Москва : Машиностроение, 1966. 573 с.

2. Белый А. Б., Карпенко Г. Д., Мышкин Н. К. Структура и методы формирования износостойких слоев. Москва : Машиностроение, 1991. 208 c.

3. Kmita A., Zych J., Holtzer M. Ecological waterbased protective coatings for moulds and cores of iron castings. Metallurgy. Vol.55. No.4, October 2016. P. 589-592.

4. Лахтин Ю.М. Металловедение и термическая обработка металлов. Москва : Металлургия, 1993. $448 \mathrm{c}$.

5. Timofeeva L. A., Timofeev S. S., Demin A. Yu., Voskoboinikov D. G. Raising of the tribotechnical properties of parts from iron-carbon alloys. Metal Science and Heat Treatment. 2019. P. 38-43.

6. Timofeeva L. A., Timofeev S. S., Demin A. Yu., Fedchenko I. I. and Voskoboinikov D. G. Surface Modification of the parts of Iron-Carbon Alloys Working at Friction and Wear. International Scientific Journal. 2018. P. 283-289.

7. Устенко О. В., Саркісян К. М. Аналіз методів та експертна оцінка оперативного контролю технічного стану колісних пар рухомого складу. Збірник наукових праць УкрДУЗТ, 2017. Вип. 173. C. 107-114.
С. С. Тимофеев, М. В. Скляров, И. И. Федченко, Р. В. Букин, Д. Г. Воскобойников. Определение скорости износа базовых элементов вагонов в эксплуатации.

Аннотация. В статье проведен анализ пассажирских и грузовых вагонов, подаваемых в плановый ремонт. В результате исследований износа деталей вагонов рассмотрен альтернативный подход, который заключается в использовании комбинированного критерия, который ограничивает межремонтный период календарной продолжительностью и выполненным объемом работы, выраженным в километрах пробега вагона в процессе эксплуатации. Установлено, что скорости износа базовых элементов вагонов, приписанных к депо, позволяют определить потребность депо в запасных элементах при новой системе ремонта вагонов в зависимости от их пробега. Ключевые слова: скорость износа, параметры оценки, эксплуатация, ремонт, размеры износа, статистические методы.

S. S. Timofeev, M. V. Sklyarov, I. I. Fedchenco, R. V. Bukin, D. G. Voskoboinikov. Determination of the rate of wear base of elements of cars in operation.

Abstract. The article analyzes passenger and freight cars that are submitted for scheduled repairs. As a result of wear and tear research, an alternative approach is considered, which is to use a combined criterion that limits the period of overhaul to calendar time and the amount of work expressed in kilometers of vehicle run during operation. For the development of a combined criterion based on an automated system of standardized accounting of carriage of wagons, taking into account real conditions of use and intensity of use, taking into account statistics, the wagons were divided into three groups. The article presents natural observations of the condition of knots and parts of wagons during the experiment. The dimensions of the base elements, which are worn in real time, were measured on all cars.

The statistics of average wear of the base element of the wagon and the coefficient of change of the rate of wear of the elements of the wagon are given.

The value of the coefficient of variation was given an estimate of the law of distribution of a random variable the rate of wear of the main elements of cars.

The obtained values of average speed of wear and scattering revealed that for some elements of the car (sleeves of spindles, wedges, breads, earrings, central beams) it is necessary to reduce their speed of wear and accordingly to increase the inter-repair run of the car before repair of the depot. This is done by applying a hard alloy to the worn surfaces of the elements. During the experiment, the measurement of wear and certain wear rates of the wagon elements showed the need to introduce 
into the depot the input control of the hardness of the wagon replacement elements. It is established that the coefficient of deterioration of the basic elements of passenger cars, carried to the depot, allows to determine the need for the depot in the spare parts for the new system of repair of cars, depending on their mileage.

Keywords: speed of wear, evaluation parameters, operation, repair, wear dimensions, statistical methods.

$$
\text { Надійшла 20.06.2019 p. }
$$

Тимофєєв Сергій Серхійович, доктор. техн. наук. Украӥнський державний університет залізничного транспорту, Харків, Украӥна. E-mail: mtv@kard.edu.иа .ORCID: https://orcid.org/0000-0002-1980-9841

Скляров Микола Вячеславович, кандидат технічних наук, Національна академія Національної гвардї Украӥни. E-mail: $\quad$ mtv@kard.edu.ua. ORSID:https://orcid.org/0000-0001-8332-6599

Федченко Ірина Іванівна, кандидат технічних наук, Украӥнський державний університет залізничного mранспорту, Харків, Украӥна.E-mail: mtv@kard.edu.иа, ORSID: https://orcid.org/0000-0002-4873-8181

Букін Роман Віталійович, аспірант кафедри якості, стандартизації, сертифікації та технологї виготовлення матеріалів, Украӥнський державний університет залізничного транспорту, Харків, Україна.E-mail: mtv@kard.edu.иа, тел.0955593551

Воскобойников Дмитро Геннадійович, аспірант кафедри якості, стандартизації, сертифікації та технології виготовлення матеріалів, Український державний університет залізничного транспорту, Харків, Украӥна. E-mail: mtv@kard.edu.иа

Timofeev Sergey Sergeevich, Dr. of tehn. sciences, Ukrainian State University of Railway Transport, E-mail: mtv@kard.edu.ua ,ORCID: https://orcid.org/0000-00021980-9841

Sklyarov Mykola Vyacheslavovich, cand. of tehn. sciences, National Academy of National Guard of Ukraine, E-mail: mtv@kard.edu.ua. ORSID:https://orcid.org/00000001-8332-6599

Fedchenko Irina Ivanovna, cand. of tehn. sciences, Ukrainian State University of Railway Transport, E-mail: mtv@kard.edu.ua ,ORCID: https://orcid.org/0000-00024873-8181

Bukin Roman Vitaliyovich, post-graduate student of the department of quality, standardization, certification and technology of materials manufacturing, Ukrainian State University of Railway Transport, E-mail: mtv@kard.edu.ua.tel:0955593551

Voskobojnikov Dmitry Gennadiyovich, post-graduate student of the department of quality, standardization, certification and technology of materials manufacturing, Ukrainian State University of Railway Transport, E-mail: mtv@kard.edu.ua 